\title{
Flavonoids as Potential Cardiopharmacological Substanses
}

\author{
Khushmatov S Shunkor* \\ Doctor of Biological Science, Institute of Biophysics and Biochemistry at the National University of Uzbekistan, Uzbekistan \\ *Corresponding Author: Doctor of Biological Science, Institute of Biophysics and Biochemistry at the National University of Uzbekistan, \\ Uzbekistan.
}

Received: June 18, 2019; Published: June 26, 2019

DOI: $10.31080 /$ ASPS.2019.03.0327

Nowadays, in pharmaceutical industry researches find cure against many various diseases, the direction of tendency is observed towards the growth of interest to search and create medical products based on bioflavonoids. Development of this field depends on having many advantageous pharmacological viewpoints of flavonoids. Many plant types containing flavonoids have been used in traditional Oriental medicine for thousands of years [1]

Flavonoids are unique secondary metabolites are synthesized in almost all plant cells, exhibiting high biological activity and due to their properties increasingly finding wide practical application in pharmacology and medicine. A wide range of biological activities and low toxicity puts them in a row promising compounds in this respect. Therefore, in pharmaceutical industry researches find cure against many various diseases, the direction of tendency is observed towards the growth of interest to search and create medical products based on bioflavonoids [2,3].

Cardio-pharmacological experimental studies in conditions in vitro/in vivo and traditional medical literature point to the cardiovascular effects of bioflavonoids in many instances [4]. The experimental results indicated the potential inotropic and anti-arrhythmic effects of flavonoids in treating cardiovascular diseases. In the investigations is shown, that a positive inotropic effect on rat papillary muscles that can be explained with the increase of [cAMP] in and may depend on increase of $\left[\mathrm{Ca}^{2+}\right]$ in. Also, another possible mechanism of the positive inotropic effect of flavonoids on the rat papillary muscles can be inhibited $\mathrm{Na}^{+} / \mathrm{K}^{+-}$ATPase via activation of reverse-function of the $\mathrm{Na}^{+} / \mathrm{Ca}^{2+}$-exchange which increase $\left[\mathrm{Ca}^{2+}\right]$ in. And some flavonoids may induce a negative inotropic effect in rat cardiac muscles and this effect at least partly be mediated by NO/ cGC/cGMP/PKG pathway [5].

And, reported, that the inotropic/antiarrhythmic effects of the flavonoid fractions may have been related to functional modulation of $\mathrm{Na}+-$ and $\mathrm{Ca}^{2+}$-channels in cardiomyocytes $[6,7]$.
In conclusion, the intense interest in the development of cardiovascular pharmacological drugs means that flavonoids may represent potential cardiopharmacological substanses in the quest to develop of a new generation of cardiovascular drugs.

\section{Bibliography}

1. Middleton E., et al. "The effects of plant flavonoids on mammalian cells: implications for inflammation, heart disease, and cancer". Pharmacological Review 52 (2000): 673-751.

2. Curin Y and Andriantsitohaina R. "Polyphenols as potential therapeutical agents against cardiovascular diseases". Pharmacological Reports 57 (2005): 97-107.

3. Narayana., et al. "Bioflavonoids classification, pharmacological, biochemical effects and therapeutic potential". Indian Journal of Pharmaceutical sciences 33 (2001): 2-16.

4. Khushmatov ShS., et al. "The inotropic effects of 3'4'-dimetyl quercetin in isolated rat papillary muscle”. European Journal of Medicine 9.3 (2015): 170-179.

5. Khushmatov Sh.S., et al. "Possible involvement of NO-synthase in inotropic effect of 4,5-dihydroxy-7-methoxyflavon in rat cardiac muscle". Open Access Journal of Translational Medicine and Research (USA). 1.3 (2017): 00014. - P.2/1-2/7.

6. Khushmatov S.S., et al. "Comparison of inotropic and antiarrhythmic activity of flavonoids - quercetin, rutin and (+)-catechin". Russian Journal of Cardiology 11 (2015): 35-41.

7. Khushmatov Sh.S., et al. "Antiarrhythmic activity of the flavonoid fraction of Plantago major L. extract". Pharmaceutical Chemistry Journal 52.9 (2019): 992-995.

Volume 3 Issue 7 July 2019

(C) All rights are reserved by Khushmatov S Shunkor. 